This document is the accepted manuscript version of the following article:

Biswakarma, J., Kang, K., Borowski, S. C., Schenkeve1d, W. D. C., Kraemer, S. M., Hering, J. G., \& Hug, S. J. (2019). Fe(II)-catalyzed ligand-controlled dissolution of iron(hydr)oxides. Environmental Science and Technology, 53(1), 88-97. https:// doi .org/10.1021/acs. est. 8 b03910

\title{
Fe(II)-catalyzed ligand-controlled dissolution of iron(hydr)oxides
}

4

${ }^{1}$ Eawag, Swiss Federal Institute of Aquatic Science and Technology, W\&T, CH-8600 Dübendorf, Switzerland

${ }^{2}$ ETH, Swiss Federal Institute of Technology Zurich, IBP, CH-8092 Zürich, Switzerland

${ }^{3}$ University of Vienna, Dept. of Environmental Geosciences, 1090 Vienna, Austria

${ }^{4}$ EPFL, Swiss Federal Institute of Technology Lausanne, ENAC, CH-1015 Lausanne, Switzerland

* Corresponding author. E-mail: stephan.hug@eawag.ch

\# current address: Randolph-Macon College, Department of Chemistry, 114 College Avenue, Ashland VA. 23005-5505, USA

${ }^{\dagger}$ Current address: Copernicus Institute, Faculty of Geosciences, Utrecht University

Princetonlaan 8A, 3584 CB Utrecht, the Netherlands 


\section{Abstract}

Dissolution of iron(III)phases is a key process in soils, surface waters and the ocean. Previous studies found that traces of $\mathrm{Fe}(\mathrm{II})$ can greatly increase ligand controlled dissolution rates at acidic $\mathrm{pH}$, but the extent that this also occurs at circumneutral $\mathrm{pH}$ and what mechanisms are involved are not known. We addressed these questions with infrared spectroscopy and ${ }^{57} \mathrm{Fe}$ isotope exchange experiments with lepidocrocite (Lp) and $50 \mu \mathrm{M}$ ethylenediaminetetraacetate (EDTA) at pH 6 and 7. Addition of 0.2-10 $\mu \mathrm{M} F e(I I)$ led to an acceleration of the dissolution rates by factors of 7-31. Similar effects were observed after irradiation with $365 \mathrm{~nm}$ UV light. The catalytic effect persisted under anoxic conditions, but ceased as soon as air or phenanthroline was introduced. Isotope exchange experiments showed that added ${ }^{57} \mathrm{Fe}$ remained in solution, or quickly re-appeared in solution when EDTA was added after ${ }^{57} \mathrm{Fe}(\mathrm{II})$, suggesting that catalyzed dissolution occurred at or near the site of ${ }^{57} \mathrm{Fe}$ incorporation at the mineral surface. Infrared spectra indicated no change in the bulk, but changes in the spectra of adsorbed EDTA after addition of Fe(II) were observed. A kinetic model shows that the catalytic effect can be explained by electron transfer to surface Fe(III) sites and rapid detachment of Fe(III)EDTA due to the weaker bonds to reduced sites. We conclude that the catalytic effect of Fe(II) on dissolution of Fe(III)(hydr)oxides is likely important under circumneutral anoxic conditions and in sunlit environments.

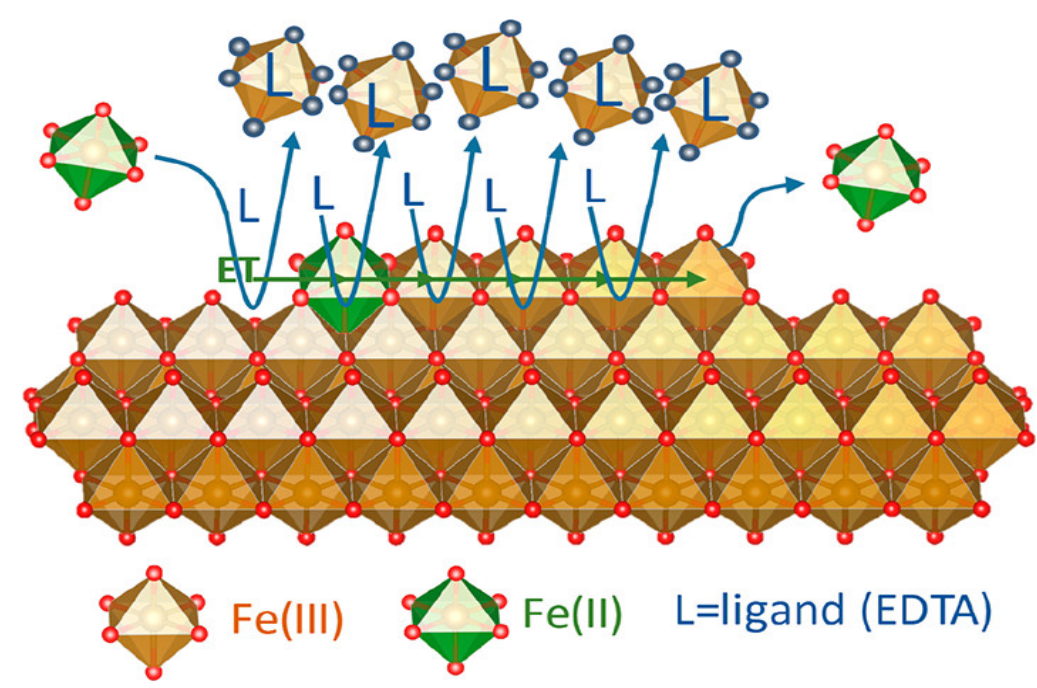




\section{Introduction}

The bioavailability of iron in oxic environments with circumneutral $\mathrm{pH}$ is limited due to the low solubility and slow dissolution kinetics of iron (oxyhydr)oxide minerals ${ }^{1}$ (here collectively termed Fe(III)(hydr)oxides). A common strategy of plants and micro-organisms for Fe acquisition involves the release of ligands (L) that promote the dissolution of Fe(III)(hydr)oxides. Laboratory and field studies have demonstrated that iron availability and rates of Fe(III)(hydr)oxide dissolution are increased by natural ligands (e.g. siderophores such as desferroxamine-B (DFOB) and aerobactin) ${ }^{2}$ and by synthetic ligands (e.g. ethylenediaminetetraacetate (EDTA). ${ }^{3}$ It has been further found that dissolution rates can be accelerated by synergistic effects between different ligands, for example between oxalate and DFOB 4, 5 and other low molecular weight organic acids and siderophores. ${ }^{6,7}$ Similar synergistic effects were observed in the dissolution of Fe(III)(hydr)oxides associated with release of trace elements. ${ }^{8} 9$

While the synergistic effects between ligands were reported to accelerate dissolution rates by factors of 2-10, ${ }^{4}$ a group of earlier studies found that a trace of Fe(II) in presence of EDTA accelerated the rate of ligand-controlled dissolution by factors of $10-100$ at low $\mathrm{pH}$ under anoxic conditions. ${ }^{10-16}$ There were no follow-up studies on the catalytic effect of Fe(II) to our knowledge until recently, and it is not known if and under what conditions the strong catalytic effect is also efficient at circumneutral pH. In a recent study, Wang et al. observed a synergistic effect between DFOB or N,N'-di(2-hydroxybenzyl)-ethylenediamine-N,N'-diacetic acid (HBED) and the reducing ligand ascorbate in the dissolution of goethite at $\mathrm{pH}$ 6. ${ }^{17}$ Similar synergistic effects were observed between ascorbate and DFOB, $2^{\prime}$-deoxymugineic acid, citrate and esculetin. ${ }^{18}$ The Fe(II) concentrations resulting from ascorbate addition were not determined, but a careful analysis of the results showed that $\mathrm{Fe}(\mathrm{II})$ acted as a catalyst for accelerated dissolution. In a subsequent study using density function theory, Kubicki et al. ${ }^{19}$ found that adsorption of Fe(II) near an Fe(III) corner site with adsorbed oxalate lead to a weakening of bonds between the corner site and the lattice, explaining a faster rate of detachment of this site from the lattice. A synergistic effect between oxalate and ascorbate was also recently reported in the extraction of arsenic from contaminated soils. ${ }^{20}$ 
The catalytic effect of Fe(II) in the earlier dissolution studies conducted at low pH has been explained as follows: Fe(II), either added or generated through reduction of surface Fe(III) by a reductant, can form ternary surface complexes, e.g. $\equiv \mathrm{Fe}(\mathrm{III})-\mathrm{L}-\mathrm{Fe}(\mathrm{II})$ (bonds to the lattice are symbolized by $\equiv)$. Electron transfer (ET) then leads to formation of $\equiv \mathrm{Fe}(\mathrm{II})-\mathrm{L}-\mathrm{Fe}(\mathrm{III})$ and rapid detachment of $\mathrm{Fe}(\mathrm{III}) \mathrm{L}$ into solution due to the relatively weaker Fe(II)-L bonds compared to Fe(III)-L bonds. Detachment of $\mathrm{Fe}(\mathrm{II})$ then leads to formation of new ternary surface complexes and to accelerated dissolution in a catalytic cycle.

Several more recent studies found that Fe(II) adsorption on Fe(III)(hydr)oxides, in the absence of ligands, can lead to isotopic exchange and recrystallization of the mineral ${ }^{21-28}$ and suggested a mechanism for the recrystallization that might also provide alternative explanations for $\mathrm{Fe}(\mathrm{II})$ catalyzed dissolution. The recrystallization was explained by a model in which electrons transferred from adsorbed Fe(II) to the surface are mobile within the Fe(III)(hydr)oxide bulk solid. This leads to formation of $\mathrm{Fe}(\mathrm{III})$ and growth at the site of initial Fe(II) adsorption and to formation and detachment of Fe(II) and thus dissolution at a remote surface site. ${ }^{21}$ Based on the studies on Fe(II)-catalyzed recrystallization and on the observations and suggestions by Wang et al. and Schenkeveld et al. ${ }^{17,}{ }^{18}$, delocalization of charge in the mineral structure could play an important role in the accelerated $\mathrm{Fe}(\mathrm{II})$-catalyzed dissolution of Fe(III)(hydr)oxides.

In a new approach to study dissolution of Fe(III)(hydr)oxides, we applied Attenuated Total Reflectance Fourier-transformed Infrared (ATR-FTIR) spectroscopy to examine the dissolution of lepidocrocite (Lp) and to observe structural changes in the bulk and on the surface before and during the dissolution process continuously with high time resolution (no filtration is required). We used ATRFTIR previously to study the structure and the photoreactions of surface complexes of citrate, ${ }^{29}$ DFOB and aerobactin ${ }^{30}$ and of dicarboxylates, ${ }^{31}$ but not to follow changes in Lp structure and its dissolution. In studies by Borer et al., ${ }^{32-35}$ we investigated light induced photo-reductive dissolution of Lp in the absence and presence of DFOB and aerobactin, considering Fe(II) as a reaction product but not its potential autocatalytic role. ${ }^{32-35}$. In the current study, we address the catalytic effect of Fe(II) in the nonreductive ligand-controlled dissolution in the dark, with added and photo-generated Fe(II). Isotope ex- 
periments with ${ }^{57} \mathrm{Fe}(\mathrm{II})$ were used to probe the fate of added $\mathrm{Fe}(\mathrm{II})$ and the importance of charge migration and isotopic exchange. Further, we applied kinetic modeling to test if proposed mechanisms are able to describe experimental results. Lp was chosen due its relevance in the environment and EDTA as a model ligand for non-reducing siderophores with predominantly carboxylate groups and due to its applications in fertilizers to increase the solubility of iron in soils. Fe(II) catalyzed dissolution might be an important pathway in the dissolution of iron(III) phases in sub- and anoxic environments, e.g. in soils and sediments, and in the oxic-anoxic interface in shallow lakes, wetlands and irrigated fields. Photoproduced Fe(II) might accelerate dissolution of iron(III) phases in sunlit oxic environments, e.g. in the ocean and in the atmosphere. Studies addressing these questions at circumneutral $\mathrm{pH}$ (which have not been conducted so far) are of particular interest because the solubility of $\mathrm{Fe}(\mathrm{III})$ phases is minimal in this pH-range. In a parallel study, the effect of added Fe(II) is investigated with Lp, goethite, hematite and 2-line ferrihydrite and the ligands HBED and DFOB over a larger $\mathrm{pH}$ range. ${ }^{36}$

\section{Materials and Methods}

\section{Chemicals and Solutions}

All chemicals used were of analytical grade and are listed in Table S1. Aqueous solutions were prepared using high-purity doubly-deinonized (DDI) water (Barnstead Nanopure). To perform studies on isotope exchange and Lp dissolution, a $20 \mathrm{mM}{ }^{57} \mathrm{Fe}(\mathrm{II})$ stock solution was prepared by dissolving $5.7 \mathrm{mg}{ }^{57} \mathrm{Fe}$ (Sigma-Aldrich, 95\% pure) in $100 \mu \mathrm{l} 2.5 \mathrm{M} \mathrm{HCl}$ and dilution to $5.00 \mathrm{ml}$ with DDI $\mathrm{H}_{2} \mathrm{O}$. The ${ }^{57} \mathrm{Fe}$ powder was $99 \%$ pure in Fe, with an isotopic composition of $95.06 \%{ }^{57} \mathrm{Fe}, 3.04 \%{ }^{56} \mathrm{Fe}$ and $1.86 \%{ }^{58} \mathrm{Fe}$ (Certificate of Analysis of the supplier).

\section{Lp ( $\gamma$-FeOOH) synthesis and characterization}

The synthesis of Lp was modified from Schwertmann ${ }^{37}$ and is decribed in more detail in the Supporting Information (SI). Briefly, $60 \mathrm{mM} \mathrm{FeCl}_{2}$ was purged with a stream of air and titrated with $1 \mathrm{M} \mathrm{NaOH}$ to within a pH range of 6.65 - 6.76 in a strongly stirred solution, until $\mathrm{NaOH}$ consumption ceased. After 2 h, the bright orange suspended particles were collected by centrifugation and repeatedly washed by resuspension and centrifugation with DDI water. Finally, the solid was collected and dried with stream of 
$\mathrm{N}_{2}$. The purity and the properties of the synthesized Lp were determined by X-ray diffraction (XRD), ATR-FTIR, and scanning electron microcopy (SEM), see SI, Figures S1-S3. The specific surface area of Lp was measured as $63 \mathrm{~m}^{2} / \mathrm{g}$ by a multipoint $\mathrm{N}_{2}$ Brunauer-Emmett-Teller (BET) adsorption method (Quantachrome Nova 3200).

\section{ATR-FTIR measurements}

ATR-FTIR spectroscopy was employed to investigate the adsorption of EDTA onto Lp and to follow the dissolution of Lp at pH 6 and 7. Measurements were performed on a Biorad FTS 575C instrument equipped with a liquid $\mathrm{N}_{2}$-cooled mercury cadmium telluride (MCT) detector and a nine reflection diamond ATR unit (SensIR Technologies, Danbury, CT), as described in detail in the SI. Briefly, a thin layer of 40-60 $\mu \mathrm{g}$ Lp was deposited on the ATR crystal (diamond, $\phi 4 \mathrm{~mm}$ ). IR absorbance spectra of the layer were recorded after drying with a gentle stream of $N_{2}$. Subsequently, the layer was covered with $40 \mathrm{ml} 9.5 \mathrm{mM} \mathrm{NaCl}(38 \mathrm{ml} 10 \mathrm{mM} \mathrm{NaCl})$ and $5 \mathrm{mM}$ MES/MOPS (2 ml $100 \mathrm{mM}$ MES/MOPS stock solution). Continuous purging of the aqueous solution with high purity $\mathrm{N}_{2}$ gas led to removal of dissolved $\mathrm{O}_{2}$ and desorption of adsorbed $\mathrm{CO}_{2}$ and served to stir the solution during measurements. Residual $\mathrm{O}_{2}$ concentrations after $3 \mathrm{~h}$ were $<10 \mathrm{nM}$ (measured with a photo-luminescent probe directly in the reaction cell, see SI). At this point, a single-beam background spectrum with the Lp-layer in contact with the anoxic background electrolyte was recorded. Subsequently, difference absorbance $(\Delta \mathrm{A})$ spectra were measured continuously, every $43 \mathrm{~s}$ or $71 \mathrm{~s}$.

EDTA and Fe(II) addition. $50 \mu \mathrm{M}$ EDTA (400 $\mu \mathrm{l} 5 \mathrm{mM}$ EDTA deoxygenated stock solution) was added 180-200 s after the background spectrum was measured. Fe(II) $(0.2-10 \mu \mathrm{M})$ was added $1800 \mathrm{~s}$ after EDTA addition. Toward the end of the measurement after 6300 s, synthetic air or 1mM phenanthroline was added to examine the effect of $\mathrm{O}_{2}$ or phenanthroline on dissolution. The same experiments were performed with addition of Fe(II) $1800 \mathrm{~s}$ before addition of EDTA. Experiments at each of the seven different Fe(II) concentrations were performed in duplicate. All procedures except the illumination with UV-light were performed under weak yellow light (>550 nm), to avoid photochemical reactions with solid and dissolved Fe(III) species.

Photochemically produced Fe(II). A UV (365 nm, bandwidth $10 \mathrm{~nm}$ ) light-emitting diode (Dr. Groebel UVElektronik GmbH) was used to produce Fe(II) at the Lp surface under both anoxic ( $\left.\mathrm{N}_{2}\right)$ and oxic 
conditions (synthetic, $\mathrm{CO}_{2}$-free air). The Lp-layer immersed in the aqueous solution, was illuminated at a distance of $7.25 \mathrm{~cm}$ from the lamp through a UV-transparent glass plate covering the solution. Illumination was done twice for $900 \mathrm{~s}$ : (a) 2700-3600 s and (b) 6200-7100 s. The light intensity of the irradiation at the Lp-layer was $150 \mathrm{~W} / \mathrm{m}^{2}$ (approximately double the irradiance of natural sunlight in the range of 300-450 nm) as measured by ferrioxalate actinometry (see SI).

\section{${ }^{57} \mathrm{Fe}(\mathrm{II})$ isotope exchange and Lp dissolution with ICP-MS analysis.}

${ }^{57} \mathrm{Fe}(\mathrm{II})$ was used to investigate the fate of the added Fe(II) during the dissolution process. Batch dissolution experiments were conducted under anoxic conditions at pH 6 at room temperature. Lp suspensions (1125 $\mu \mathrm{M} \approx 0.100 \mathrm{~g} \mathrm{~L}^{-1}$ ) were prepared by dispersing $10.0 \mathrm{mg} \mathrm{Lp}$ in $100 \mathrm{ml}$ aqueous solution $(9.5 \mathrm{mM}$ $\mathrm{NaCl}$ and 5mM MES). Suspensions were purged with $\mathrm{N}_{2}$ for at least 4 h before addition of EDTA or ${ }^{57} \mathrm{Fe}(\mathrm{II}) . \mathrm{Fe}(\mathrm{II})$ was either applied after or before EDTA: (a) $1.2 \mu \mathrm{M}{ }^{57} \mathrm{Fe}(\mathrm{II})$ was injected $30 \mathrm{~min}$ after $50 \mu \mathrm{M}$ EDTA addition, and (b) 1.0 or $1.2 \mu \mathrm{M}{ }^{57} \mathrm{Fe}(\mathrm{II})$ was added 30 min before EDTA addition. The time between $\mathrm{Fe}^{2+}$ and EDTA addition made it possible to a) examine Lp dissolution in the presence of EDTA and b) to investigate isotope exchange in the absence of EDTA. Aliquots of $1.5 \mathrm{ml}$ were withdrawn periodically, filtered through a $0.1 \mu$ m nylon filters (Whatman ${ }^{\circledR}$ Puradisc 13 syringe filters) and diluted in $1 \% \mathrm{HNO}_{3}$ (Merck, suprapure) for inductively coupled plasma-mass spectrometry (ICP-MS, Agilent 7500ce) analysis. The dissolution of Lp was followed at mass 56, with counts calibrated to represent the total concentration of all iron isotopes from Lp. Dissolution rates were determined as the slope of the linear fit of the dissolved Fe concentration as a function of time over the time-interval 6002400s after Fe(II) addition. We use the following definitions:

$\left[{ }^{56} \mathrm{Fe}\right]{ }_{\text {diss }} \quad$ Concentration of dissolved ${ }^{56} \mathrm{Fe}$ multiplied with 1.092 to represent the total dissolved iron (sum of all iron isotopes) released from Lp. $\left(5.85 \%{ }^{54} \mathrm{Fe}, 91.57 \%{ }^{56} \mathrm{Fe}, 2.12 \%{ }^{57} \mathrm{Fe}\right.$, $0.28 \%{ }^{58} \mathrm{Fe}$ ). This is the concentration of Fe as usually measured with ICP-MS at mass 56, with counts calibrated with certified standard solutions. ${ }^{56} \mathrm{Fe}$ comes from dissolution of Lp or from exchange of added ${ }^{57} \mathrm{Fe}$ with ${ }^{56} \mathrm{Fe}$ from Lp. We corrected for the $3 \%{ }^{56} \mathrm{Fe}$ impurity in 1-1.2 $\mu \mathrm{M}$ added ${ }^{57} \mathrm{Fe}$. This correction is small $(<0.04 \mu \mathrm{M})$ compared to the concentrations of ${ }^{56} \mathrm{Fe}$ released from Lp by isotope exchange and dissolution. 
$\left[{ }^{57} \mathrm{Fe}\right]_{\text {diss }}$ Concentration of dissolved ${ }^{57} \mathrm{Fe}$. Measured with ICP-MS at mass 57 and calibrated with normal certified Fe standards, considering that they contain $2.12 \%{ }^{57} \mathrm{Fe}$.

$\left[{ }^{57} \mathrm{Fe}\right]$ tracer, diss $\quad$ To follow the concentration of ${ }^{57} \mathrm{Fe}$ added as a tracer, we subtracted the ${ }^{57} \mathrm{Fe}$ coming from dissolution or isotope exchange with Lp: $\left[{ }^{57} \mathrm{Fe}\right]_{\text {tracer, diss }}=\left[{ }^{57} \mathrm{Fe}\right]_{\text {diss }}$ $0.0212\left[{ }^{56} \mathrm{Fe}\right]^{*}$ diss.

(The subtracted concentration of ${ }^{57} \mathrm{Fe}$ from dissolution of Lp is $1.06 \mu \mathrm{M}$, when $50 \mu \mathrm{M}$ $\mathrm{Fe}(\mathrm{III})$ is dissolved in the presence of $50 \mu \mathrm{M}$ EDTA).

\section{Results and Discussion}

\section{Lp dissolution monitored with ATR-FTIR}

Fig 1A shows the ATR-FTIR absorbance spectrum of a Lp layer and a SEM image of the Lp in the inset. The Lp consists of plate-like (50-100 nm width and 200-500 nm length) aggregates of 200-500 nm long rods of $10 \mathrm{~nm}$ width and less than $10 \mathrm{~nm}$ thickness. The IR spectrum shows the characteristic vibrations of Lp at $1160 \mathrm{~cm}^{-1}, 1021 \mathrm{~cm}^{-1}$. The full spectrum shown in Figure S1 also shows the characteristic band of rod-shaped Lp at $752 \mathrm{~cm}^{-1}$ (in contrast to plate-shaped Lp where this band is located at $742 \mathrm{~cm}^{-1}$ ). ${ }^{38}$ Figure 1B shows ATR-FTIR difference absorbance $(\Delta \mathrm{A})$ spectra recorded during EDTA adsorption over 1800 seconds at $\mathrm{pH} 6$ under anoxic condition. Addition of $50 \mu \mathrm{M}$ EDTA at $\mathrm{t}=180-220 \mathrm{~s}$ lead to characteristic IR absorbance bands in the range of $1700-1200 \mathrm{~cm}^{-1}$ that increased in the first few minutes and then reached a stable level. There are two distinct peaks of adsorbed EDTA at $1570 \mathrm{~cm}^{-1}$ and 1408 $\mathrm{cm}^{-1}$, which were assigned to the asymmetric and symmetric vibrations of carboxylate groups, respectively. ${ }^{39}$ There was an increase, but no significant change in the shape of the spectra during EDTA adsorption. This shows that at $\mathrm{pH} 6.0$ one single surface complex, or several complexes in constant proportions, were formed on the Lp layer. Complexes with different spectral characteristics are formed at lower pH (SI, Figure S4). The adsorption of EDTA led to a small decrease to the left of and a small increase to the right of the absorbance peak of Lp. These small changes in absorbance must be due to local changes in the coordination environment of the Lp lattice at the surface related to adsorption of EDTA, but are not interpreted further. Importantly, there was only a minimal decrease at $1021 \mathrm{~cm}^{-1}$ for 
the entire duration of the first $1800 \mathrm{~s}$, indicating that there was only minor dissolution of Lp in the presence of EDTA alone.

The group of spectra in (C) show a decrease in absorbance at $1021 \mathrm{~cm}^{-1}$, indicating a strong acceleration in dissolution of Lp after addition of $1 \mu \mathrm{M}$ Fe(II). Minor spectral changes (which will be discussed later) were recorded in the spectra of adsorbed EDTA upon addition of $1 \mu \mathrm{M} \mathrm{Fe(II).} \mathrm{Introduc-}$ tion of synthetic air or $1 \mathrm{mM}$ phenanthroline at $6300 \mathrm{~s}$ stopped the accelerated dissolution of Lp. The effect of air indicates a rapid oxidation of Fe(II) at the surface, which ends the catalytic effect of Fe(II) on dissolution. Phenanthroline addition caused rapid formation of Fe(II)-phenanthroline complexes in the solution and apparently also fast desorption of $\mathrm{Fe}(\mathrm{II})$ from the surface or complexation of $\mathrm{Fe}(\mathrm{II})$ at the surface, which ended the catalytic action of Fe(II). These results show the importance of the presence of $\mathrm{Fe}(\mathrm{II})$ or $\mathrm{Fe}(\mathrm{II}) \mathrm{EDTA}$ for the catalytic effect on the dissolution processes. Similar observations were made when $10 \mu \mathrm{M}$ Fe(II) was added $3000 \mathrm{~s}$ after $50 \mu \mathrm{M}$ EDTA at pH 7 (see SI, Fig S6).

Fig. 2 shows the kinetics of EDTA adsorption and Lp dissolution at pH 6 under anoxic condition (data points every $43 \mathrm{~s}$ ). EDTA adsorption was examined at $1408 \mathrm{~cm}^{-1}$ and Lp dissolution at $1021 \mathrm{~cm}^{-1}$. EDTA adsorbed rapidly and reached equilibrium within $600 \mathrm{~s}$ after EDTA addition. There is virtually no decrease of the absorbance at $1021 \mathrm{~cm}^{-1}$, indicating a low rate of dissolution in the presence of only EDTA. Increasing concentrations of Fe(II) $(0.2-10 \mu \mathrm{M})$ were added $1800 \mathrm{~s}$ after $50 \mu \mathrm{M}$ EDTA addition. A clear catalytic effect was observed already for sub-micro molar concentrations of added Fe(II) with a strongly accelerated decrease of absorbance at $1021 \mathrm{~cm}^{-1}$. The same effect at sub-micromolar concentrations were observed in a parallel study with two different ligands (HBED and DFOB) and several Fe(III)(hydr)oxides ${ }^{36}$. The plots in Fig. 2 show that the dissolution rates started to increase quickly after addition of $\mathrm{Fe}(\mathrm{II})$ and that the decrease in absorbance after $\mathrm{Fe}(\mathrm{II})$ addition was linear over time from $3000-6000 \mathrm{~s}$. At the same time, the absorbance of EDTA at $1408 \mathrm{~cm}^{-1}$ showed no visible change for 0.1$1.0 \mu \mathrm{M}$ added Fe(II). With 6-10 $\mu \mathrm{M}$ added Fe(II), the absorbance decreased quickly and then remained at a stable level. This indicates that a steady-state dissolution rate was reached within 30-120 s, which remained constant throughout our ATR-FTIR experiments. The fast decrease in absorbance at $1408 \mathrm{~cm}^{-}$ ${ }^{1}$ and the changes in the spectra of adsorbed EDTA for $6 \mu \mathrm{M}$ and $10 \mu \mathrm{M} \mathrm{Fe}(\mathrm{II})$ will be discussed in the last section. The order in which EDTA and Fe(II) were added did not alter the main observations. When 
$1 \mu \mathrm{M}$ Fe(II) was added $1800 \mathrm{~s}$ before $50 \mu \mathrm{M}$ EDTA, no changes were recorded for Lp at $1021 \mathrm{~cm}^{-1}$ (see SI, Fig. S4). After EDTA was added, approximately the same rate of decline in absorbance (-0.033 units after $6000 \mathrm{~s}$ ) was reached as when EDTA was added first (-0.032 units after 6000s) . 1 mM phenanthroline addition after $\sim 8800 \mathrm{~s}$ again stopped the accelerated Lp dissolution.

To determine dissolution rates, slopes were calculated from the linear ranges of the decreasing absorbances at $1021 \mathrm{~cm}^{-1}$ in Figure 2. (The ranges were 900-1200 s for EDTA only and 3000-5000 s in the presence of $\mathrm{Fe}(\mathrm{II}))$. The rates of Lp dissolution expressed in \% of Lp dissolved per time were calculated from the slopes divided by the initial absorbance of Lp at $1021 \mathrm{~cm}^{-1}$ for each experiment. The initial absorbances of the Lp layers in the different experiments varied in the range of 0.7-0.9 and are listed in SI, Table S2. Figure 3 presents the rate of Lp dissolution as a function of added Fe(II) concentrations. In the range of 0.2-2 $\mu \mathrm{M}, \mathrm{Fe}(\mathrm{II})$, the rate of Lp dissolution increased close to linearly with increasing concentrations of added Fe(II), after which the increase leveled off. The solid line corresponds to a fit with a kinetic model which is described in a later section.

Photochemically produced Fe(II). The kinetics of EDTA adsorption and Lp dissolution, during experiments in which Fe(II) was photo-chemically generated at pH 6.0, are shown in Fig. 4.. EDTA (50 $\mu \mathrm{M})$ was added after 180-220 s and EDTA adsorption reached an equilibrium within $600 \mathrm{~s}$ under both anoxic and oxic conditions. Again, there was only very minimal Lp dissolution in the presence of EDTA alone. Under UV-illumination (for 900 s) absorbances at 1408 and $1021 \mathrm{~cm}^{-1}$ immediately started to change. The absorbance at $1408 \mathrm{~cm}^{-1}$ (adsorbed EDTA) decreased and stabilized at a lower level during illumination, while the absorbance at $1021 \mathrm{~cm}^{-1}$ (Lp) decreased linearly under both anoxic and oxic conditions. We attribute this mainly to photolysis of Fe(III)-EDTA surface complexes and formation of Fe(II) directly on the Lp surface, due to the high photoreactivity of the adsorbed EDTA, ${ }^{16}$ but intrinsic photo-processes of Lp with formation of Fe(II) and OH-radicals could also have contributed to EDTA degradation. ${ }^{34}$ From the decrease in the absorbance of Lp, we estimate that $0.14-0.25 \mu \mathrm{M}$ Fe(II) were formed during each illumination (see SI). After the illumination stopped, photolyzed EDTA was replaced by EDTA from solution which can be seen by the recovery of the absorbance at $1408 \mathrm{~cm}^{-1}$. Also, Lp dissolution under oxic condition almost instantly came to a halt after illumination. In contrast, under 
anoxic conditions, Lp dissolution continued in the dark, yet at a slower rate. During a second UV-illumination (from 6200-7100 s) under anoxic conditions, more Lp was dissolved than during the first illumination and the subsequent dissolution rate in the dark continued at a faster rate. Apparently, $\mathrm{Fe}(\mathrm{II})$ produced during the second illumination was added to Fe(II) formed in the first illumination and thus increased the concentration of photogenerated Fe(II) and the catalytic effect of $\mathrm{Fe}$ (II) during and after the illumination. The catalytic effect was not observed under oxic conditions, where the second illumination lead to the same rate and amount of dissolution as the first illumination and to essentially no dissolution in the absence of light. We ascribe this to fast oxidation of the formed adsorbed Fe(II) by dissolved $\mathrm{O}_{2}$. Similar observations were made in experiments at pH 7 (see SI, Fig S7). These results demonstrate a continuing catalytic effect of photochemically produced $\mathrm{Fe}(\mathrm{II})$ on non-reductive ligandcontrolled dissolution at pH 6 and 7 after illumination stops under anoxic conditions. Qualitatively, the dissolution rates after illumination are similar to those with $0.2-0.5 \mu \mathrm{M}$ added Fe(II) immediately after the illumination stops, and about half of these rates a few minutes later. Since Fe(II) is formed directly at the surface and equilibration with the solution might take a few minutes, the observed Fe(II) catalyzed dissolution rates agree well with the effect of the estimated 0.14-0.25 $\mu \mathrm{M} \mathrm{Fe(II)} \mathrm{in} \mathrm{the} \mathrm{solution} \mathrm{volume}$ of $40 \mathrm{ml}$.

${ }^{57} \mathbf{F e}$ (II) isotope exchange and Lp (lepidocrocite) dissolution. To determine the fate of Fe added as Fe(II) before and during Lp dissolution, we performed dissolution experiments in which we added Fe(II) as ${ }^{57} \mathrm{Fe}(\mathrm{II})$.

Figure 5A shows Lp dissolution as a function of time before and after addition of $1.2 \mu \mathrm{M}^{57} \mathrm{Fe}(\mathrm{II})$ to a Lp suspension $(1125 \mu \mathrm{M})$ containing $50 \mu \mathrm{M}$ EDTA at pH 6.0 under anoxic conditions. The dissolved concentrations of iron coming from dissolution of Lp, $\left[{ }^{56} \mathrm{Fe}\right]^{*}$ diss, are plotted as purple triangles on the right y-axis. In agreement with the FTIR results, the dissolution of Lp was very slow in the absence of $\mathrm{Fe}(\mathrm{II})$. After addition of ${ }^{57} \mathrm{Fe}(\mathrm{II})$, the dissolution was strongly accelerated and $\left[{ }^{56} \mathrm{Fe}\right]^{*}$ diss reached $42 \mu \mathrm{M}$ after 1600s, approaching the expected limit of Fe(III) solubility with $50 \mu \mathrm{M}$ EDTA. The dissolved concentrations of added ${ }^{57} \mathrm{Fe}$ are plotted as orange squares on the left y-axis ([ $\left.\left.{ }^{57} \mathrm{Fe}\right]_{\text {tracer, diss }}\right)$. Importantly, added ${ }^{57} \mathrm{Fe}$ remained in the solution in the presence of EDTA. This shows that the added ${ }^{57} \mathrm{Fe}$ (added as ${ }^{57} \mathrm{Fe}(\mathrm{II})$ ) was not incorporated into the surface or bulk during dissolution. A decrease in 
$\left[{ }^{57} \mathrm{Fe}\right]_{\text {tracer, diss }}$ would have been observed if adsorption of ${ }^{57} \mathrm{Fe}(\mathrm{II})$ and incorporation as ${ }^{57} \mathrm{Fe}(\mathrm{III})$ by electron transfer would have led to preferential dissolution of surface sits or surfaces which are different from the sites of adsorption and incorporation.

In the presence of EDTA, rapid electron transfer at the Lp-surface could have resulted in oxidation of added ${ }^{57} \mathrm{Fe}$ (II) to ${ }^{57} \mathrm{Fe}(\mathrm{III})$. We cannot comment on the oxidation state of ${ }^{57} \mathrm{Fe}$ tracer,diss in the presence of EDTA; addition of phenanthroline (phen) to filtered solutions resulted in only very low and inconsistent UV absorbance, which did not allow quantification of Fe(II)(phen) ${ }_{3}$. Even so, it is clear that ${ }^{57} \mathrm{Fe}$ added in the presence of EDTA was not incorporated into the solid.

Figure 5B shows ${ }^{57} \mathrm{Fe}$ isotope exchange and Lp dissolution with reversed addition of ${ }^{57} \mathrm{Fe}(\mathrm{II})$ and EDTA. In the following, we first discuss the observations before addition of EDTA, when the oxidation state of measurable dissolved Fe can only be Fe(II), followed by the observations after EDTA addition, where the oxidation state of dissolved Fe is mixed, but predominantly Fe(III).

In contrast to addition of ${ }^{57} \mathrm{Fe}(\mathrm{II})$ in the presence of EDTA, we observed an immediate decrease in the concentration of the added 1.0-1.2 $\mu \mathrm{M}{ }^{57} \mathrm{Fe}$ (II) (orange squares, left y-axis) in the absence of EDTA, presumably by adsorption. This was followed by a slower decrease in $\left[{ }^{57} \mathrm{Fe}(\mathrm{II})\right]$, coupled with an increase of $\left[{ }^{56} \mathrm{Fe}(\mathrm{II})\right]^{*}$ diss (red triangles, left y-axis), indicating isotope exchange between Fe(II) in solution and Fe from Lp over the $1800 \mathrm{~s}$ before EDTA was added. The sum of these concentrations (green circles on the left y-axis) was 1.0-1.1 $\mu \mathrm{M}$, meaning that 0.1-0.2 $\mu \mathrm{M}$ of the added Fe(II) remain adsorbed. Since $\left[{ }^{56} \mathrm{Fe}\right]{ }^{*}$ diss increased from 0 to $0.70 \mu \mathrm{M}$, up to $0.7 \mu \mathrm{M}{ }^{57} \mathrm{Fe}(\mathrm{II})$ must have been incorporated into the surface as ${ }^{57} \mathrm{Fe}(\mathrm{III})$. Thus, before EDTA addition, both adsorption and isotope exchange, but no dissolution was observed. This is in agreement with studies showing isotope exchange between dissolved $\mathrm{Fe}(\mathrm{II})$ and $\mathrm{FeOOH}$ that leads to recrystallization on longer time scales ${ }^{21-28}$.

After addition of EDTA, a rapid increase of $\left[{ }^{56} \mathrm{Fe}\right]^{*}$ diss (purple triangles, right axis ) due to catalyzed Lp dissolution was observed. At the same time, the added (tracer) ${ }^{57} \mathrm{Fe}$ that was previously adsorbed and/or exchanged was released back into solution. Over $80 \%$ of the adsorbed/exchanged ${ }^{57} \mathrm{Fe}$ was in solution after dissolution of $10 \mu \mathrm{M}$ Lp within the first $1000 \mathrm{~s}$ after addition of EDTA.

This observation shows that added ${ }^{57} \mathrm{Fe}$ was not preferentially incorporated into surface sites or surfaces that were less prone to dissolution upon addition of EDTA. Although this observation does not exclude 
ET to other sites and other surfaces, such ET (if it occurs) does not result in the preferential dissolution of those other sites or surfaces.

We can, in the main, exclude preferential dissolution distant from the site at which added ${ }^{57} \mathrm{Fe}$ was adsorbed, since addition of EDTA resulted in release of $>80 \%$ of the added tracer ${ }^{57} \mathrm{Fe}$ back into solution. The initially adsorbed ${ }^{57} \mathrm{Fe}$ (i.e., $1 \mu \mathrm{M}$ of the added $1.2 \mu \mathrm{M}{ }^{57} \mathrm{Fe}$ ) corresponds to only $5.7 \%$ of the total active surface site concentration of $17.5 \mu \mathrm{M}$ (calculated for $100 \mathrm{mg} \mathrm{Lp} / \mathrm{L}$ with a surface area of $6.3 \cdot 10^{18} \mathrm{~nm}^{2} / \mathrm{L}$ assuming 1.67 active site per $\mathrm{nm}^{2} .^{40}$ If ET had resulted in preferential dissolution at different surface sites and surfaces (with only the natural abundance of ${ }^{57} \mathrm{Fe}$ ) then no increase in $\left[{ }^{57} \mathrm{Fe}\right]_{\text {tracer, diss }}$ should have been observed (recall that the reported $\left[{ }^{57} \mathrm{Fe}\right]_{\text {tracer, diss }}$ was corrected for the natural abundance of ${ }^{57} \mathrm{Fe}$ in Lp) . Even if dissolution had occurred randomly at all surface sites (enriched to $5.7 \%{ }^{57} \mathrm{Fe}$ ), dissolution of $10 \mu \mathrm{M} \mathrm{Lp}$ would have resulted in a maximum tracer concentration $\left[{ }^{57} \mathrm{Fe}\right]_{\text {tracer, diss }}$ of $0.57 \mu \mathrm{M}$. Incorporation of a minor faction of ${ }^{57} \mathrm{Fe}$ (added before EDTA) into more stable sites and surfaces is, however, consistent with the association of $10-20 \%$ of the added ${ }^{57} \mathrm{Fe}$ with the solid even after dissolution of $50 \mu \mathrm{M}$ Lp (i.e., measured as $\left[{ }^{56} \mathrm{Fe}\right]^{*}$ diss).

Our observations do not exclude charge injection and charge migration in the Lp surface and bulk lattice that lead to recrystallization on a longer time scale. In the presence of a ligand that promotes dissolution, mobile charge can be transferred back to previously adsorbed or incorporated ${ }^{57} \mathrm{Fe}$ and accelerate its dissolution. An alternative explanation for the fast dissolution of the added ${ }^{57} \mathrm{Fe}$ is the formation of a less crystalline or amorphous ${ }^{57} \mathrm{Fe}(\mathrm{III})$ phases that are dissolved more quickly than Lp after addition of EDTA. However, a surface precipitate with addition of only 1-1.2 $\mu \mathrm{M}$ Fe(II) to a Lp suspension with estimated $17.5 \mu \mathrm{M}$ surface sites seems less likely than adsorption and isotope exchange by incorporation of ${ }^{57} \mathrm{Fe}$ into the surface.

Possible phase changes. We observed no evidence for transformation of Lp to goethite or magnetite with $0.2-10 \mu \mathrm{M}$ added Fe(II) (to which FTIR is very sensitive, see Figure S3) in our experiments. Previous studies found exchange of ${ }^{55} \mathrm{Fe}$ between Lp and dissolved Fe(II) $(0.2-1.0 \mathrm{mM}) \mathrm{Fe}(\mathrm{II})$ at $\mathrm{pH}$ 6.5, ${ }^{41}$, ${ }^{42}$ but only minor formation of magnetite even with $1 \mathrm{mM}$ dissolved Fe(II) after 2 days ${ }^{41}$ and no formation of goethite over 7 days. ${ }^{42}$ 
Kinetic model for the catalytic effect of Fe(II). In our experiments, ligand controlled dissolution was slow compared to Fe(II)-catalyzed dissolution. We define the measured catalytic effect (CE) as $\mathrm{R}_{\text {diss,L,Fe(II) }} / \mathrm{R}_{\text {diss,L, }}$, where $\mathrm{R}_{\text {diss,L,Fe(II) }}$ and $\mathrm{R}_{\text {diss,L } \mathrm{L}}$ are the dissolution rates in the presence and absence of $\mathrm{Fe}(\mathrm{II})$, respectively. As defined, CE was 1 without added Fe(II) and ranged from 7-31 with 0.2-10 $\mu \mathrm{M}$ added Fe(II), as listed in Table S3.

To explore reaction mechanisms that can explain the catalytic effect of Fe(II), a kinetic model was developed that allowed us to fit the model outputs to measured data by optimizing rate coefficients and concentrations of active surface sites in the model. Tentative reaction mechanisms for Fe(II) catalyzed dissolution have been presented before for dissolution at low $\mathrm{pH},{ }^{10,43,44}$ but it has not been shown that they can quantitatively explain experimental results. The model with reaction equations is presented in Table 1 and is described in more detail in the SI.

We assumed that all equilibrium reactions are fast and not rate determining for dissolution on the investigated time scale. As consequence of the fast equilibration in reactions R1-R5, the order of the addition of EDTA and Fe(II) should not change the observation of the catalytic effect, as was experimentally observed (Figure S4). The competitive adsorption of formed Fe(III)EDTA (R6) can explain the nonlinear dissolution in the batch-experiments, with dissolution rates that decrease more strongly from 1800-5000 s (Figure 5) than expected from the decreasing concentration of uncomplexed EDTA. In the dissolution measured with FTIR (Figure 2) this effect was not observed and dissolution proceeded linearly, which can be explained by the much lower Lp concentrations in the AFR-FTIR experiments. With maximally 8\% dissolution of $60 \mu \mathrm{g}$ Lp in $40 \mathrm{ml}$, dissolved Fe(III)EDTA concentration remained below 1.4 $\mu \mathrm{M}$. When $20 \mu \mathrm{MFe}(\mathrm{III})$ was added (Figure S8) the dissolution rate also decreased. Similar nonlinear dissolution kinetics were observed previously in the photo-reductive dissolution of Lp with aerobactin, ${ }^{33}$ where decreasing rates in the presence of added and formed $\mathrm{Fe}(\mathrm{III})$ were also ascribed to competing adsorption of formed Fe(III)-ligand complexes with the free ligand. By variation of rate coefficients (see SI), we found that either the electron transfer (ET) in R7 or the detachment of Fe(III)L can be defined as the rate determining step in this model. Since Fe(II)EDTA is strongly reducing, we assumed that ET is the faster step and adjusted the rate coefficient for detachment of $\mathrm{Fe}(\mathrm{III}) \mathrm{L}\left(\mathrm{k}_{8}\right)$ in 
reaction R8 as the rate determining step. The listed fitted rate coefficients lead to good fits of the currently available data, but they are tentative because the rate coefficients for reactions R4 and R5 correspond to reactions (i.e., adsorption of EDTA on adsorbed Fe(II) or adsorption of Fe(II)EDTA) that yield the same surface complex in our model. Since more than $99.8 \%$ of Fe(II) is complexed by EDTA, the rate coefficients for these reactions are not independent, as explained in more detail in the SI.

Important parameters in the model are the concentrations of active sites for the dissolution reactions ( $\mathrm{p}_{1}$ to $\mathrm{p}_{4}$ ). The site concentrations for the adsorption of Fe(II), EDTA and Fe(III)EDTA were obtained from adsorption data as shown in Figure S11. They agree with ranges for iron(hydr)oxides reported in the literature. ${ }^{45}, 46 \mathrm{~A}$ lower concentration of sites that are active for dissolution has been used in models describing the dissolution of hematite ${ }^{47}$ and agrees with the understanding that dissolution proceeds on kink and step sites ${ }^{48}$ whose concentrations are smaller than the sum of adsorption sites measured in adsorption experiments.

Structure of surface complexes. In the kinetic model, we formulate the surface complexes that involve both $\mathrm{Fe}(\mathrm{II})$ and EDTA as $\equiv \mathrm{Fe}^{\prime \prime \prime}-\mathrm{Fe} \mathrm{e}^{\prime \prime} \mathrm{L}$, but they could alternatively be formulated as $\equiv \mathrm{Fe} \mathrm{e}^{\mathrm{II}}-\mathrm{L}-\mathrm{Fe}$ " or as complexes with Fe(II) adsorbed next to a site were EDTA is adsorbed. Ideally, the infrared spectra could provide information about the structure of the complex involving both Fe(II) and EDTA. Addition of Fe(II) caused shifts in the spectra of adsorbed EDTA to higher energy and induced spectral changes around several peak positions (see SI, Fig. S9, SI Table S4). This clearly indicates that the interaction of Fe(II) with adsorbed EDTA led to formation of additional complexes at the surface, or that additional complexes were formed by adsorption of Fe(II)EDTA from solution. However, the shifts could not be interpreted in terms of structures. In a recently published study on the formation of oxalate complexes on Lp, we found that several surface complexes with different structures were formed. For oxalate, detailed DFT calculations allowed us to draw conclusions about the structures of these different surface complexes. ${ }^{49}$ DFT calculations with the larger ligand EDTA in the presence of Fe(II) are computationally more demanding and were not attempted in this study.

Reaction mechanisms and possible implications. Fe(II) accelerates the dissolution of Lp by EDTA when added before or after addition of EDTA. At pH 6, most of the added Fe(II) (>80\%) remains in solution even in the absence of EDTA. In the presence of $50 \mu \mathrm{M}$ EDTA, over $>99.8 \%$ of dissolved 
Fe(II) and $>99.9 \%$ of Fe(III) are complexed with EDTA (Table S5). Most likely, the Fe(II) catalyzed dissolution is driven by adsorption of Fe(II)EDTA and formation of mixed Fe(II)-Fe(III) ternary surface complexes (reaction R5 in Table 1), followed by electron transfer and detachment of Fe(III)EDTA (R7R8). We can currently not determine the fraction of adsorbed Fe(II)EDTA and whether the newly formed $\mathrm{Fe}(\mathrm{II})$ (R9) is complexed with EDTA directly at the surface (reaction R4) or leaves the surface (back reaction of R3) and reabsorbs as Fe(II)EDTA (R5) to continue the catalytic cycle. The model constitutes a useful list of possible reactions that can explain our observation, but more work is required to quantitatively determine the contribution of each of these reactions and to determine the corresponding rate coefficients.

\section{Environmental significance}

We observed that added and photo-produced Fe(II) can accelerate the dissolution of Lp with EDTA by a factor of 7-30 at pH 6 and at pH 7 under anoxic conditions. Fe(II) catalyzed dissolution could be an efficient strategy for accelerated mobilization and uptake of iron in environments with changing redox conditions and in sunlit environments where Fe(II) is produced photochemically. Examples are soils where reducing conditions are not sufficient for reductive dissolution of Fe-bearing phases, but where traces of Fe(II) could lead to strongly accelerated Fe(II)-catalyzed dissolution in the presence of synthetic or natural ligands (e.g. siderophores), ${ }^{18}$ as also shown in our parallel study for a range of minerals with HBED and DFOB. ${ }^{36}$ Other environments where Fe(II)-catalyzed dissolution could be important are oxic-anoxic transition zones in lakes, wetlands, and irrigated agricultural fields. Added Fe(II) and photoproduced Fe(II) did not appear lead to formation of mobile charge or Fe(II) that is protected from oxidation by oxygen, e.g. by charge residing in the bulk of the solid, at least not with Lp. Nevertheless, steady state concentrations of photo-produced Fe(II) at the surface of iron oxide particles under sunlit conditions could make Fe(II)-catalyzed dissolution an important pathway in their photoreductive dissolution. It is also possible that negative charge from added or produced Fe(II) can persist longer in the bulk of more conductive iron(hydr)oxide minerals and that this results in a longer lasting catalytic effect 
of Fe(II) under oxic conditions. The time resolved ATR-FTIR measurements and ${ }^{57} \mathrm{Fe}$ isotope experiments presented here have proven useful and will be used to investigate the effect of Fe(II) on the dissolution of other Fe(III)(hydr)oxide phases in different environments.

\section{Associated Content}

Supporting Information. List of chemicals; lepdicrocite synthesis and characterization (XRD and FTIR spectra); details on ATR-FTIR measurements, list of duplicate experiments; FTIR spectra of adsorbed EDTA with $\mathrm{pH}$ and concentration dependence, spectral changes with added Fe(II)); input file for kinetic model, model fits for dissolution kinetics and adsorption isotherms. (5 Tables, 12 Figures).

\section{Acknowledgements}

We thank Thomas Ruettimann (Eawag) for ICP-MS analyses and for technical assistance. We also thank Numa Pfeninger (Eawag) for BET and XRD measurements and Dr. Ralf Kaegi (Eawag) for SEM images. This project was financially supported by the Swiss National Science Foundation, project number 200021L_150150 “Synergistic effects of redox processes and ligand controlled dissolution of iron(hydr)oxide phases” Mathematics, Natural sciences and Engineering (division II). SK, WS and KK were supported by the he Austrian Science Fund (FWF, Grant No.: I 1528-N19).

\section{References}

1. Kraemer, S. M., Iron oxide dissolution and solubility in the presence of siderophores. Aquat. Sci. 2004, 66 (1), 3-18.

2. Sandy, M.; Butler, A., Microbial iron acquisition: Marine and terrestrial siderophores. Chem. Rev. 2009, 109 (10), 4580-4595.

3. Shenker, M.; Chen, Y., Increasing Iron Availability to Crops: Fertilizers, Organo-Fertilizers, and Biological Approaches. J. Soil Sci. Plant Nutr. 2005, 51, (1), 1-17.

4. Cheah, S. F.; Kraemer, S. M.; Cervini-Silva, J.; Sposito, G., Steady-state dissolution kinetics of goethite in the presence of desferrioxamine $B$ and oxalate ligands: Implications for the microbial acquisition of iron. Chem. Geol. 2003, 198 (1-2), 63-75.

5. Cervini-Silva, J.; Sposito, G., Steady-state dissolution kinetics of aluminum-goethite in the presence of desferrioxamine-B and oxalate ligands. Environ. Sci. Technol. 2002, 36, (3), 337-342. 
6. Reichard, P. U.; Kraemer, S. M.; Frazier, S. W.; Kretzschmar, R., Goethite dissolution in the presence of phytosiderophores: Rates, mechanisms, and the synergistic effect of oxalate. Plant Soil 2005, 276 (1-2), 115-132.

7. Reichard, P. U.; Kretzschmar, R.; Kraemer, S. M., Dissolution mechanisms of goethite in the presence of siderophores and organic acids. Geochim. Cosmochim. Acta 2007, 71 (23), 56355650 .

8. Wolff-Boenisch, D.; Traina, S. J., The effect of desferrioxamine B, enterobactin, oxalic acid, and $\mathrm{Na}$-alginate on the dissolution of uranyl-treatedgoethite at $\mathrm{pH} 6$ and $25^{\circ} \mathrm{C}$. Chem. Geol. 2007, 243, (3-4) 357-368.

9. Liu, X.; Fu, J. W.; Da Silva, E.; Shi, X. X.; Cao, Y.; Rathinasabapathi, B.; Chen, Y.; Ma, L. Q., Microbial siderophores and root exudates enhanced goethite dissolution and Fe/As uptake by As-hyperaccumulator Pteris vittata. Environ. Pollut. 2017, 223, 230-237.

10. Blesa, M. A.; Borghi, E. B.; Maroto, A. J. G.; Regazzoni, A. E., Adsorption of EDTA and iron-EDTA complexes on magnetite and the mechanism of dissolution of magnetite by EDTA. J. Colloid Interface Sci. 1984, 98 (2), 295-305.

11. Suter, D.; Siffert, C.; Sulzberger, B.; Stumm, W., Catalytic dissoluion of iron(III)(hydr)oxides by oxalic acid in the presence of Fe(II). Naturwissenschaften 1988, 75 (11), 571-573.

12. Borghi, E. B.; Regazzoni, A. E.; Maroto, A. J. G.; Blesa, M. A., Reductive dissolution of magnetite by solutions containing EDTA and Fell. J. Colloid Interface Sci. 1989, 130 (2), 299-310.

13. Wehrli, B.; Sulzberger, B.; Stumm, W., Redox processes catalyzed by hydrous oxide surfaces. Chem. Geol. 1989, 78 (3-4), 167-179.

14. Torres, R.; Blesa, M. A.; Matijević, E., Interactions of metal hydrous oxides with chelating agents. IX. Reductive dissolution of hermatite and magnetite by aminocarboxylic acids. J. Colloid Interface Sci. 1990, 134 (2), 475-485.

15. Suter, D.; Banwart, S.; Stumm, W., Dissolution of Hydrous Iron(III) Oxides by Reductive Mechanisms. Langmuir 1991, 7 (4), 809-813.

16. Karametaxas, G.; Hug, S. J.; Sulzberger, B., Photodegradation of EDTA in the Presence of Lepidocrocite. Environ. Sci. Technol. 1995, 29 (12), 2992-3000.

17. Wang, Z.; Schenkeveld, W. D. C.; Kraemer, S. M.; Giammar, D. E., Synergistic Effect of Reductive and Ligand-Promoted Dissolution of Goethite. Environ. Sci. Technol. 2015, 49, (12), 7236-7244.

18. Schenkeveld, W. D. C.; Wang, Z.; Giammar, D. E.; Kraemer, S. M., Synergistic Effects between Biogenic Ligands and a Reductant in Fe Acquisition from Calcareous Soil. Environ. Sci. Technol. 2016, 50 (12), 6381-6388.

19. Kubicki, J. D.; Tunega, D.; Kraemer, S., A density functional theory investigation of oxalate and $\mathrm{Fe}(\mathrm{II})$ adsorption onto the (010) goethite surface with implications for ligand- and reductionpromoted dissolution. Chem. Geol. 2017, 464, 14-22.

20. Lee, J. C.; Kim, E. J.; Baek, K., Synergistic effects of the combination of oxalate and ascorbate on arsenic extraction from contaminated soils. Chemosphere 2017, 168, 1439-1446.

21. Handler, R. M.; Beard, B. L.; Johnson, C. M.; Scherer, M. M., Atom exchange between aqueous Fe(II) and goethite: An Fe isotope tracer study. Environ. Sci. Technol. 2009, 43 (4), 1102-1107.

22. Gorski, C. A.; Scherer, M. M., Fe2+ sorption at the Fe oxide-water interface: A revised conceptual framework. In ACS Symposium Series, American Chemical Society: 2011; Vol. 1071, pp 315-343.

23. Gorski, C. A.; Handler, R. M.; Beard, B. L.; Pasakarnis, T.; Johnson, C. M.; Scherer, M. M., Fe atom exchange between aqueous Fe2+ and magnetite. Environ. Sci. Technol. 2012, 46 (22), 1239912407.

24. Latta, D. E.; Gorski, C. A.; Scherer, M. M., Influence of Fe2+-catalysed iron oxide recrystallization on metal cycling. Biochem. Soc. Trans. 2012, 40, (6), 1191-1197.

25. Handler, R. M.; Frierdich, A. J.; Johnson, C. M.; Rosso, K. M.; Beard, B. L.; Wang, C.; Latta, D. E.; Neumann, A.; Pasakarnis, T.; Premaratne, W. A. P. J.; Scherer, M. M., Fe(II)-catalyzed recrystallization of goethite revisited. Environ. Sci. Technol. 2014, 48 (19), 11302-11311. 
26. Joshi, P.; Fantle, M. S.; Larese-Casanova, P.; Gorski, C. A., Susceptibility of Goethite to Fe2+Catalyzed Recrystallization over Time. Environ. Sci. Technol. 2017, 51 (20), 11681-11691.

27. Joshi, P.; Gorski, C. A., Anisotropic Morphological Changes in Goethite during Fe2+-Catalyzed Recrystallization. Environ. Sci. Technol. 2016, 50 (14), 7315-7324.

28. Zarzycki, P.; Rosso, K. M., Stochastic Simulation of Isotopic Exchange Mechanisms for Fe(II)Catalyzed Recrystallization of Goethite. Environ. Sci. Technol. 2017, 51 (13), 7552-7559.

29. Borer, P.; Hug, S. J.; Sulzberger, B.; Kraemer, S. M.; Kretzschmar, R., Photolysis of citrate on the surface of lepidocrocite: An in situ attenuated total reflection infrared spectroscopy study. J. Phys. Chem. C 2007, 111 (28), 10560-10569.

30. Borer, P.; Hug, S. J.; Sulzberger, B.; Kraemer, S. M.; Kretzschmar, R., ATR-FTIR spectroscopic study of the adsorption of desferrioxamine $B$ and aerobactin to the surface of lepidocrocite $(\gamma$ FeOOH). Geochim. Cosmochim. Acta 2009, 73 (16), 4661-4672.

31. Borer, P.; Hug, S. J., Photo-redox reactions of dicarboxylates and $\alpha$-hydroxydicarboxylates at the surface of Fe(III)(hydr)oxides followed with in situ ATR-FTIR spectroscopy. J. Colloid Interface Sci. 2014, 416, 44-53.

32. Borer, P. M.; Sulzberger, B.; Reichard, P.; Kraemer, S. M., Effect of siderophores on the lightinduced dissolution of colloidal iron(III) (hydr)oxides. Mar. Chem. 2005, 93, 179- 193.

33. Borer, P.; Kraemer, S. M.; Sulzberger, B.; Hug, S. J.; Kretzschmar, R., Photodissolution of lepidocrocite $(\gamma-\mathrm{FeOOH})$ in the presence of desferrioxamine $\mathrm{B}$ and aerobactin. Geochim. Cosmochim. Acta 2009, 73 (16), 4673-4687.

34. Borer, P.; Sulzberger, B.; Hug, S. J.; Kraemer, S. M.; Kretzschmar, R., Wavelength-dependence of photoreductive dissolution of lepidocrocite $(\gamma-\mathrm{FeOOH})$ in the absence and presence of the siderophore DFOB. Environ. Sci. Technol. 2009, 43 (6), 1871-1876.

35. Borer, P.; Sulzberger, B.; Hug, S. J.; Kraemer, S. M.; Kretzschmar, R., Photoreductive dissolution of iron(III) (Hydr)oxides in the absence and presence of organic ligands: Experimental studies and kinetic modeling. Environ. Sci. Technol. 2009, 43 (6), 1864-1870.

36. Kang, K.; Schenkeveld, W. D. C.; Biswakarma, J.; Borowski, S. C.; Hug, S. J.; Hering, J. G.; Kraemer, S. M., Low Fe(II) concentrations catalyze the dissolution of various Fe(III) (hydr)oxide minerals in the presence of diverse ligands and over a broad pH range. Environ. Sci. Technol. 2018.

37. Schwertmann, U.; Cornell, R. M., Iron Oxides in the Laboratory. 2nd, Completely Revised and Extended Edition ed.; Wiley-VCH Weinheim, Germany, 2000.

38. Cornell, R. M.; Schwertmann, U., The Iron Oxides: Structure, Properties, Reactions, Occurrences, and Uses. 2nd ed.; ed.; Wiley-VCH: New York, NY, USA, 2003.

39. Norén, K.; Loring, J. S.; Bargar, J. R.; Persson, P., Adsorption mechanisms of EDTA at the wateriron oxide interface: Implications for dissolution. J. Phys. Chem. C 2009, 113, (18), 7762-7771.

40. Zhang, Y.; Charlet, L.; Schindler, P. W., Adsorption of protons, Fe(II) and AI(III) on lepidocrocite ( $\gamma$-FeOOH). Colloids Surf. 1992, 63, (3-4), 259-268.

41. Pedersen, H. D.; Postma, D.; Jakobsen, R.; Larsen, O., Fast transformation of iron oxyhydroxides by the catalytic action of aqueous Fe(II). Geochim. Cosmochim. Acta 2005, 69, (16), 3967-3977.

42. Jones, A. M.; Collins, R. N.; Rose, J.; Waite, T. D., The effect of silica and natural organic matter on the Fe(II)-catalysed transformation and reactivity of Fe(III) minerals. Geochim. Cosmochim. Acta 2009, 73 (15), 4409-4422.

43. Ballesteros, M. C.; Rueda, E. H.; Blesa, M. A., The influence of iron (II) and (III) on the kinetics of goethite dissolution by EDTA. J. Colloid Interface Sci. 1998, 201, (1), 13-19.

44. Banwart, S.; Davies, S.; Stumm, W., The role of oxalate in accelerating the reductive dissolution of hematite ( $\alpha$-Fe2O3) by ascorbate. Colloids Surf. 1989, 39 (2), 303-309.

45. Nowack, B.; Lutzenkirchen, J.; Behra, P.; Sigg, L., Modeling the adsorption of metal-EDTA complexes onto oxides. Environ. Sci. Technol. 1996, 30 (7), 2397-2405.

46. Nowack, B.; Sigg, L., Adsorption of EDTA and metal-EDTA complexes onto goethite. J. Colloid Interface Sci. 1996, 177 (1), 106-121. 
47. Samson, S. D.; Eggleston, C. M., The depletion and regeneration of dissolution-active sites at the mineral-water interface: II. Regeneration of active sites on alpha-Fe2O3 at pH 3 and pH 6. Geochim. Cosmochim. Acta 2000, 64 (21), 3675-3683.

48. Wehrli, B., Monte Carlo simulations of surface morphologies during mineral dissolution. J. Colloid Interface Sci. 1989, 132 (1), 230-242.

49. Borowski, S. C.; Biswakarma, J.; Kang, K.; Schenkeveld, W. D. C.; Hering, J. G.; Kubicki, J. D.; Kraemer, S. M.; Hug, S. J., Structure and reactivity of oxalate surface complexes on lepidocrocite derived from infrared spectroscopy, DFT-calculations, adsorption, dissolution and photochemical experiments. Geochim. Cosmochim. Acta 2018, 226, 244-262. 
Tables and Figures

Table. 1. Kinetic model with list of reactions and fitted equilibrium constants, rate coefficients and surface site concentrations for $\mathrm{pH} 6.0$ and $9.5 \mathrm{mM} \mathrm{NaCl}{ }^{(a)}$

\begin{tabular}{|c|c|c|c|c|c|c|}
\hline Nr. & Reaction & & & Nr. of & Description & Fixed or fitted \\
\hline $\mathrm{R} 1$ & $\mathrm{Fe}^{\|}+\mathrm{L}$ & $\rightleftarrows$ & $\mathrm{Fe}^{\| \prime} \mathrm{L}$ & $\mathrm{K}_{1}$ & $\begin{array}{l}\text { Complexation of } \mathrm{Fe}^{\|} \text {in solu- } \\
\text { tion }\end{array}$ & $10.3^{(b)}$ \\
\hline $\mathrm{R} 2$ & $\equiv \mathrm{Fe}^{\prime \prime I}+\mathrm{L}$ & $\rightleftarrows$ & $\equiv \mathrm{Fe}^{I I I}-\mathrm{L}$ & $\mathrm{K}_{2}$ & Adsorption of ligand (L) & $5.0^{(c)}$ \\
\hline R3 & $\equiv \mathrm{Fe}^{\prime \prime \prime}+\mathrm{Fe}^{\| \prime}$ & $\rightleftarrows$ & $\equiv \mathrm{Fe}^{\prime \prime \prime}-\mathrm{Fe}^{\|}$ & $\mathrm{K}_{3}$ & Adsorption of Fe" & $5.5^{(\mathrm{d})}$ \\
\hline R4 & $\equiv \mathrm{Fe}^{\prime \prime \prime}-\mathrm{Fe}^{\prime \prime}+\mathrm{L}$ & $\rightleftarrows$ & $\equiv F e^{I I I}-F^{\| I}-L$ & $\mathrm{~K}_{4}$ & $\begin{array}{l}\text { Adsorption of } L \text { on adsorbed } \\
\text { Fe" }\end{array}$ & $4.7^{(\mathrm{e})}$ \\
\hline R5 & $\equiv \mathrm{Fe}^{\prime \prime \prime}+\mathrm{Fe} \mathrm{E}^{\| \prime} \mathrm{L}$ & $\rightleftarrows$ & $\equiv \mathrm{Fe}^{I I I}-\mathrm{Fe}^{\| \prime}-\mathrm{L}$ & $\mathrm{K}_{5}$ & Adsorption of Fe"L & 5.4 \\
\hline R6 & $\equiv F e^{I I I}+\mathrm{Fe}^{\prime \prime \prime I} \mathrm{~L}$ & $\rightleftarrows$ & $\equiv \mathrm{Fe}^{I I I}-\mathrm{Fe}^{\mathrm{III}}-\mathrm{L}$ & $\mathrm{K}_{6}$ & $\begin{array}{l}\text { Competing adsorption of } \\
\text { Fe"l'L }\end{array}$ & $5.7^{(\mathrm{d})}$ \\
\hline R7 & $\equiv F e^{I I I}-F^{I I}-\mathrm{L}$ & $\rightarrow$ & $\equiv \mathrm{Fe}^{\mathrm{II}}-\mathrm{Fe}^{\mathrm{III}-\mathrm{L}}$ & $k_{7(E T)}$ & Electron transfer & 1 \\
\hline R8 & $\equiv F e^{\prime \prime}-F^{\prime \prime \prime}-L$ & $\rightarrow$ & $\equiv \mathrm{Fe}^{\| \prime}+\mathrm{Fe}^{\prime \prime \prime} \mathrm{L}$ & $\mathrm{k}_{8}$ & $\begin{array}{l}\mathrm{Fe}(\mathrm{II}) \text {-catalyzed detachment } \\
\text { of Fe"II-L }\end{array}$ & -0.64 \\
\hline R9 & $\begin{array}{l}\equiv \mathrm{Fe}^{\|}+ \\
\mathrm{Lp}_{\text {bulk }}\end{array}$ & $\rightarrow$ & $\equiv \mathrm{Fe}^{\mathrm{III}}-\mathrm{Fe}^{\prime \prime}$ & $\mathrm{k}_{9}$ & $\begin{array}{l}\text { Formation of new surface } \\
\text { site }\end{array}$ & $6^{(f)}$ \\
\hline R10 & $\equiv \mathrm{Fe}^{\prime \prime \prime}-\mathrm{L}$ & $\rightarrow$ & $\equiv+F e^{\prime \prime \prime} L$ & $\mathrm{k}_{10}$ & Detachment of Fe $\mathrm{Fe}^{\mathrm{III}-\mathrm{L}}$ & -2.5 \\
\hline R11 & $\equiv+$ Lp bulk & $\rightarrow$ & $\equiv \mathrm{Fe}^{I I I}$ & $\mathrm{k}_{11}$ & $\begin{array}{l}\text { Formation of new surface } \\
\text { site }\end{array}$ & $6^{(f)}$ \\
\hline $\begin{array}{l}\text { Fittec } \\
\text { surfa }\end{array}$ & $\begin{array}{l}\text { active surfac } \\
\text { ce site conc. fo }\end{array}$ & & conc. (last co & $\begin{array}{l}\mathrm{umn},[\equiv \\
\mathrm{A}, \mathrm{Fe}(\mathrm{II})\end{array}$ & $\begin{array}{l}\left.\mathrm{e}^{\prime \prime \prime \prime}\right] /[\mathrm{Lp}](\mathrm{M} / \mathrm{M}) \text { and } \equiv \mathrm{Fe} \mathrm{e}^{\mathrm{II} / \mathrm{nm}} \\
\text { and } \mathrm{Fe}(\mathrm{III}) \mathrm{EDTA} \text { in batch exper }\end{array}$ & $\begin{array}{l}\text { for dissolution, and } \\
\text { ments }\end{array}$ \\
\hline & $\equiv \mathrm{Fe}^{I I I}$ & & & $p_{1}$ & $\begin{array}{l}\text { Dissolution in batch and FTIR } \\
\text { experiments }\end{array}$ & $\begin{array}{l}6.3 \mathrm{e}-5^{(\mathrm{g})} \\
6.7 \mathrm{e}-3 \equiv \mathrm{Fe} \mathrm{e}^{\mathrm{III}} / \mathrm{nm}^{2}\end{array}$ \\
\hline & $\equiv F e^{I I I}$ & & & $p_{2}$ & $\begin{array}{l}\text { Adsorption of EDTA with } \\
\text { FTIR }(10 \mu \mathrm{M} \text { Lp) }\end{array}$ & $\begin{array}{l}7.4 \mathrm{e}-3^{\text {(c) }} \\
0.79 \equiv \mathrm{Fe}^{\mathrm{III}} / \mathrm{nm}^{2}\end{array}$ \\
\hline & $\equiv \mathrm{Fe}^{\prime \prime \prime \prime}$ & & & $\mathrm{p}_{3}$ & $\begin{array}{l}\text { Ads. of Fe(II) in batch exper- } \\
\text { iments }\end{array}$ & $\begin{array}{l}1.0 \mathrm{e}-3^{(\mathrm{d})} \\
0.11 \equiv \mathrm{Fe}^{\mathrm{III}} / \mathrm{nm}^{2}\end{array}$ \\
\hline & $\equiv \mathrm{Fe}^{\mathrm{III}}$ & & & $\mathrm{p}_{4}$ & Ads. of Fe(III)EDTA & $\begin{array}{l}1.3 \mathrm{e}-3^{(\mathrm{d})} \\
0.14 \equiv \mathrm{Fe} \mathrm{e}^{\prime \prime \prime} / \mathrm{nm}^{2}\end{array}$ \\
\hline
\end{tabular}

(a) Surface sites $\equiv \mathrm{Fe}^{\prime \prime \prime}-\mathrm{OH}$ are abbreviated as $\equiv \mathrm{Fe}^{\prime \prime \prime}$ and surface complexes $\equiv \mathrm{Fe}^{\prime \prime \prime}-\mathrm{O}-\mathrm{Fe}^{\prime \prime}$ as $\equiv \mathrm{Fe}^{\prime \prime \prime}-\mathrm{Fe}{ }^{\prime \prime}$. Surface complexes that involve both ligand and $\mathrm{Fe}(\mathrm{II})$ in close proximity are formulated as $\equiv \mathrm{Fe} \mathrm{e}^{\mathrm{III}}-\mathrm{Fe} \mathrm{e}^{\mathrm{II}}-\mathrm{L}$. This could mean a ternary surface complexes or adsorbed EDTA next to a reduced site.

(b) Conditional complex formation constant for Fe(II)EDTA at pH 6 (see SI). (Over 99.8\% of Fe(II) is present as $\mathrm{Fe}^{\mathrm{II}} \mathrm{EDTA}^{2-}$ with $50 \mu \mathrm{M}$ EDTA).

(c) Best fits to adsorption isotherm for EDTA determined with FTIR, see SI Figures S10 and S11.

(d) Best fits to adsorption isotherms of Fe(II) and Fe(III)EDTA, see SI Table S5 and Figure S11.

(e) The rate coefficients of R4 are interdependent with the rate of Fe" detachment (back reaction R3), formation of Fe"L (R1) and adsorption of Fe"L (R5), see SI.

(f) Arbitrary, fast and non-rate determining rate coefficients.

(g) Best fits to Lp-dissolution in batch (1.13 mM Lp) and FTIR (10 $\mu \mathrm{M} \mathrm{Lp}=35.6 \mu \mathrm{g} / 40 \mathrm{ml})$ experiments, see SI. 


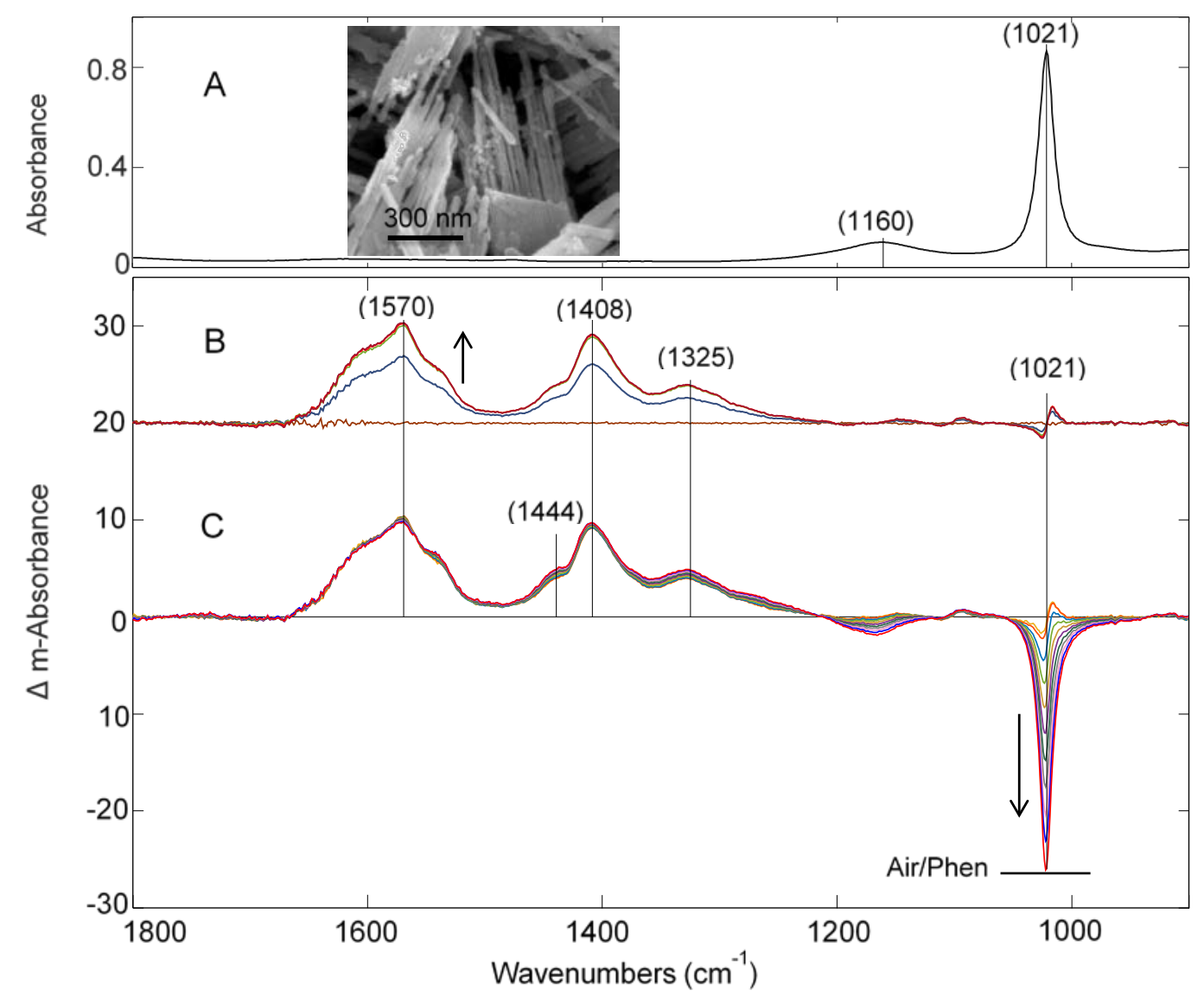

Fig.1. (A) ATR-FTIR absorbance spectrum of lepidocrocite (Lp) and SEM image of Lp (inset). (B) Difference absorbance spectra recorded during EDTA adsorption (offset by 20 units), upon addition of $50 \mu \mathrm{M}$ EDTA to a layer of 40-60 $\mu \mathrm{g}$ Lp in contact with $40 \mathrm{ml}$ aqueous solution $(10 \mathrm{mM} \mathrm{NaCl}$ and $5 \mathrm{mM}$ MES, pH 6.0). (C) Dissolution of Lp after addition of $1 \mu \mathrm{M}$ Fe(II) in presence of $50 \mu \mathrm{M}$ EDTA. Spectra were recorded continuously every $43 \mathrm{~s}$. Averages of every 10 continuous spectra are shown for clarity. All measurements were conducted at pH 6 under anoxic condition by purging the solution with high purity $\mathrm{N}_{2}$. The group of spectra in (B) shows adsorption of EDTA by the increase of peaks at $1570 \mathrm{~cm}^{-1}$ and $1408 \mathrm{~cm}^{-1}$. The spectra in (C) show the strongly accelerated dissolution of Lp by the decrease of the absorbance of Lp at $1021 \mathrm{~cm}^{-1}$ after addition of $1 \mu \mathrm{M} \mathrm{Fe}(\mathrm{II})$ ( $\mathrm{t}_{\mathrm{Fe}(\mathrm{II}) \text { addition }}=1843 \mathrm{~s}$ ). Introduction of synthetic air or $1 \mathrm{mM}$ phenanthroline (Phen) (at $\mathrm{t}=6300 \mathrm{~s}$ ) stopped the dissolution. 


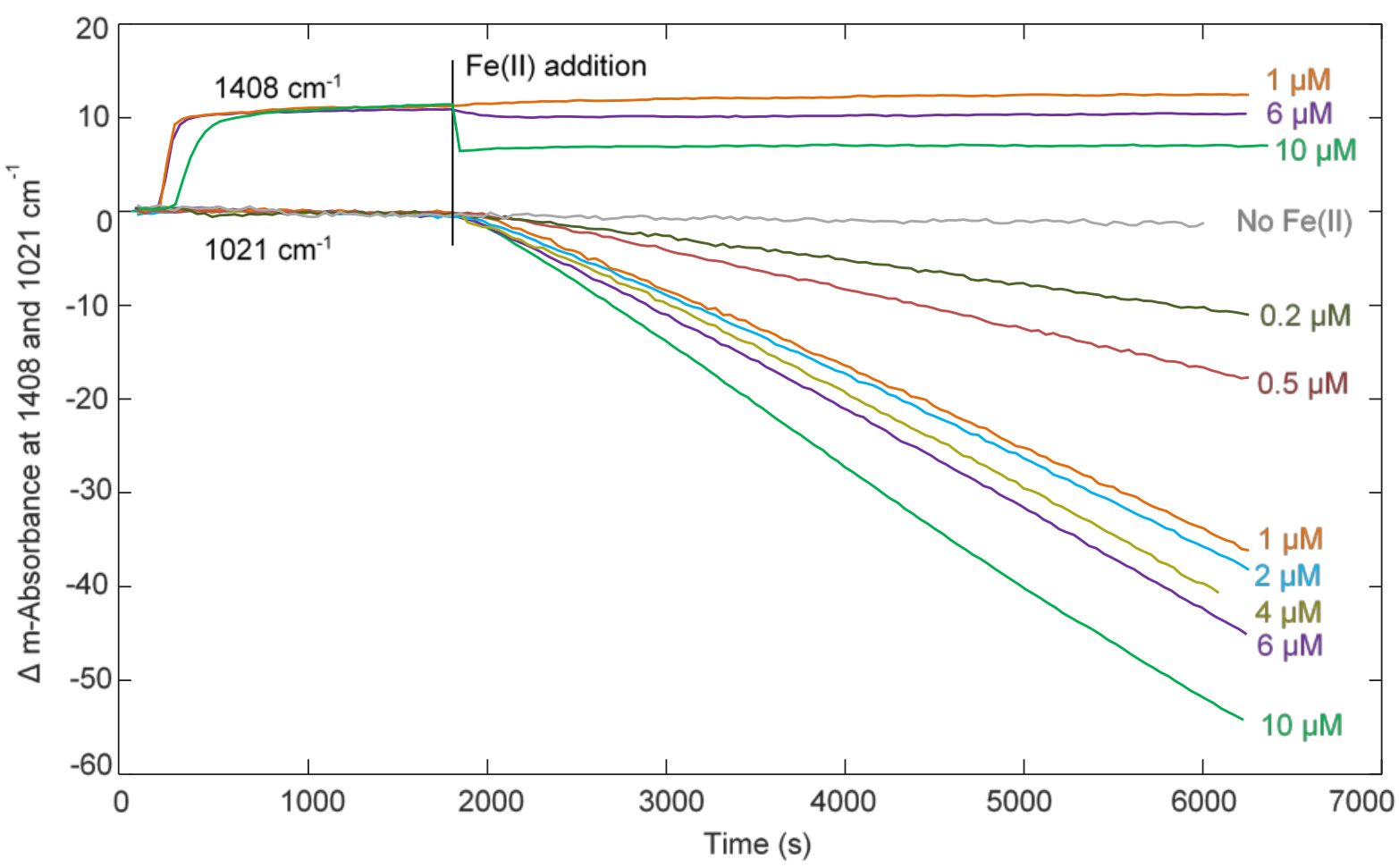

649

Fig.2. Kinetics of EDTA adsorption and Lp dissolution (pH 6.0, anoxic conditions) monitored with ATR-FTIR. Adsorption of EDTA was monitored at $1408 \mathrm{~cm}^{-1}$ and dissolution of Lp at $1021 \mathrm{~cm}^{-1}$. $50 \mu \mathrm{M}$ EDTA was added (at $\mathrm{t}=180-200 \mathrm{~s}$ ) after purging the aqueous solution covering the Lp layer with $\mathrm{N}_{2}$ for at least 3-4 h, followed by addition of $\mathrm{Fe}(\mathrm{II})(0.2-10 \mu \mathrm{M})$ after $1800 \mathrm{~s}$. EDTA adsorbed rapidly and reached equilibrium in $<600 \mathrm{~s}$. Fe(II) additions lead to accelerated dissolution of Lp. Slopes (at $1021 \mathrm{~cm}^{-1}$ ) were determined from 3000-5000 s. si (1) . 1 $(2$

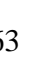

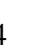

(1)




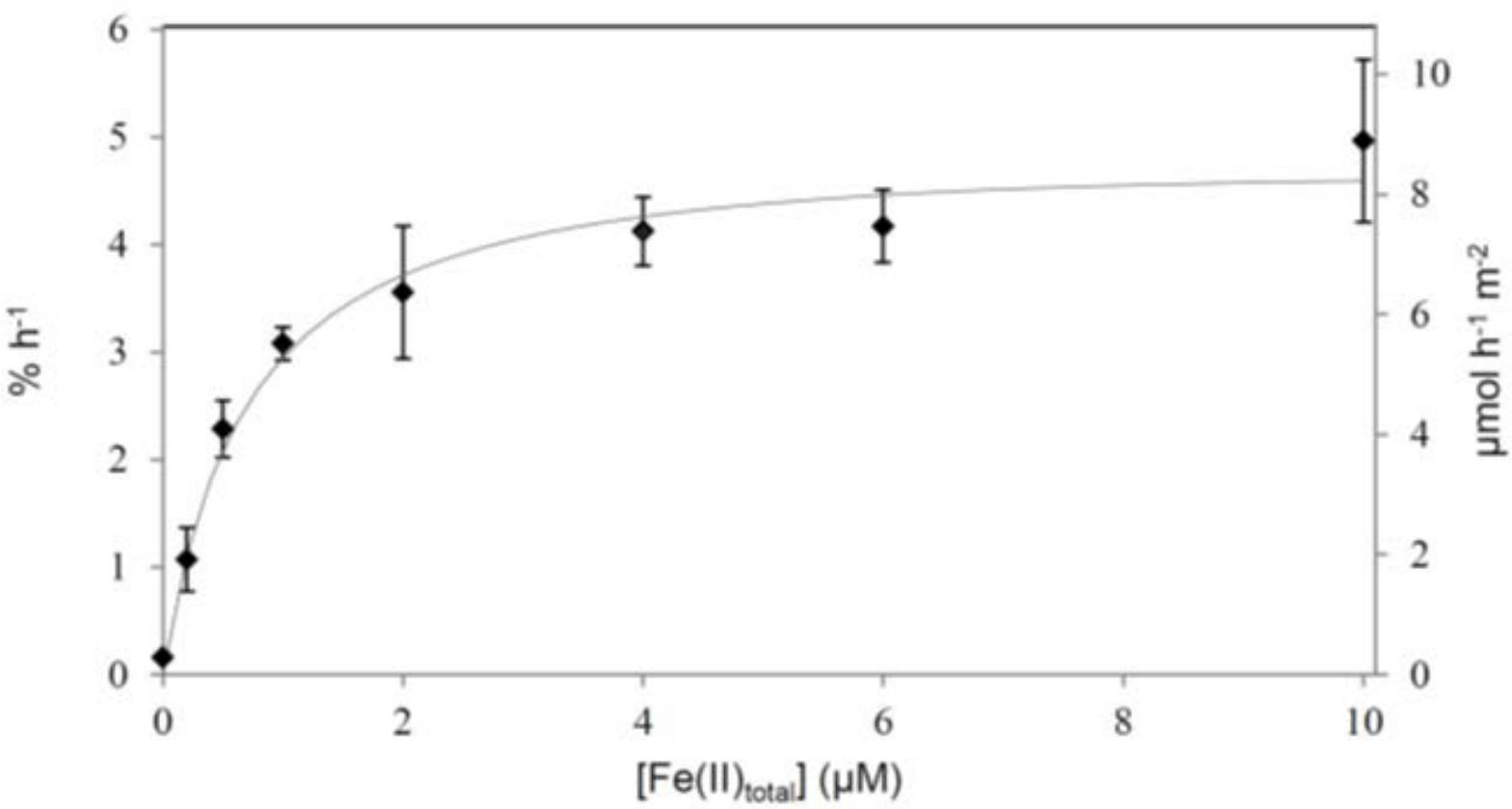
82 83

Fig.3. Rates of Lp dissolution as a function of added (total) Fe(II) concentrations. Rates expressed as $\% \mathrm{~h}^{-1}$ (left Y-axis) were calculated from the slopes of the lines in Fig. 2 divided by the initial absorbance of Lp (at $1021 \mathrm{~cm}^{-1}$ ) for each experiment. Rates expressed as $\mu \mathrm{mol} \mathrm{h} \mathrm{h}^{-1} \mathrm{~m}^{-2}$ (right $\mathrm{Y}$-axis) were calculated using the molecular weight (88.85 $\left.\mathrm{g} \mathrm{mol}^{-1}\right)$ and surface area $\left(63 \mathrm{~m}^{2} \mathrm{~g}^{-1}\right)$ of Lp. The solid line corresponds to a kinetic model (Table 1) as described in the text. (1) 7 78 679 80 81 84 


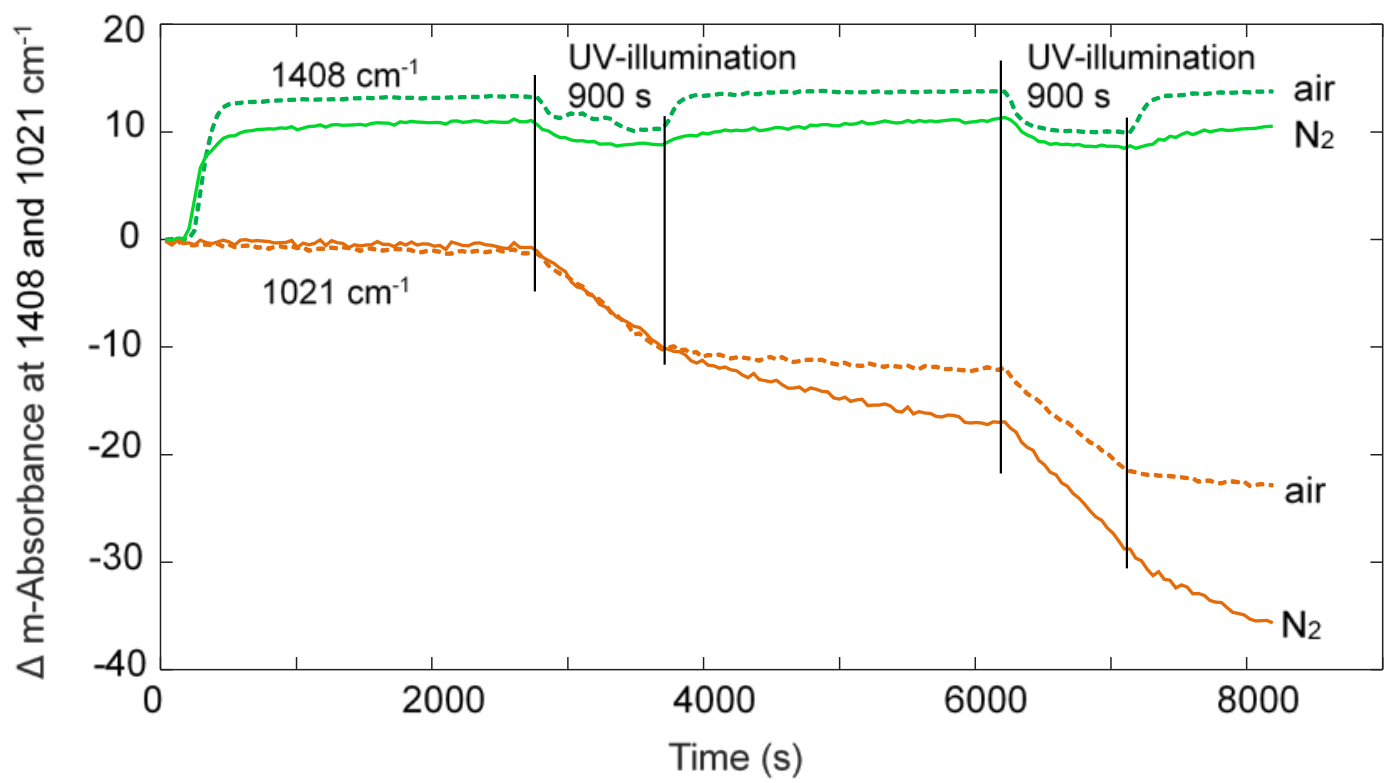

687

Fig.4. Kinetics of EDTA adsorption (monitored at $1408 \mathrm{~cm}^{-1}$ ) and dissolution of Lp (monitored at $\left.1021 \mathrm{~cm}^{-1}\right)$ at pH $6(I=0.01 \mathrm{M})$ during photochemical experiments. Dashed lines represent experiments performed under oxic conditions and solid lines under anoxic conditions. EDTA (50 $\mu \mathrm{M})$ was added at 180-220 s. During UV-illumination (for 900 s) with a 365 nm UV-LED lamp, adsorbed EDTA is photolyzed at the surface. After irradiation, photo-transformed EDTA is replaced by EDTA from solution. Lp dissolution was strongly accelerated by UV-illumination under both oxic and anoxic conditions. After irradiation stopped, there was no or very minimal continuing Lp dissolution under oxic condition. In contrast, under anoxic condition, dissolution of Lp continued. 


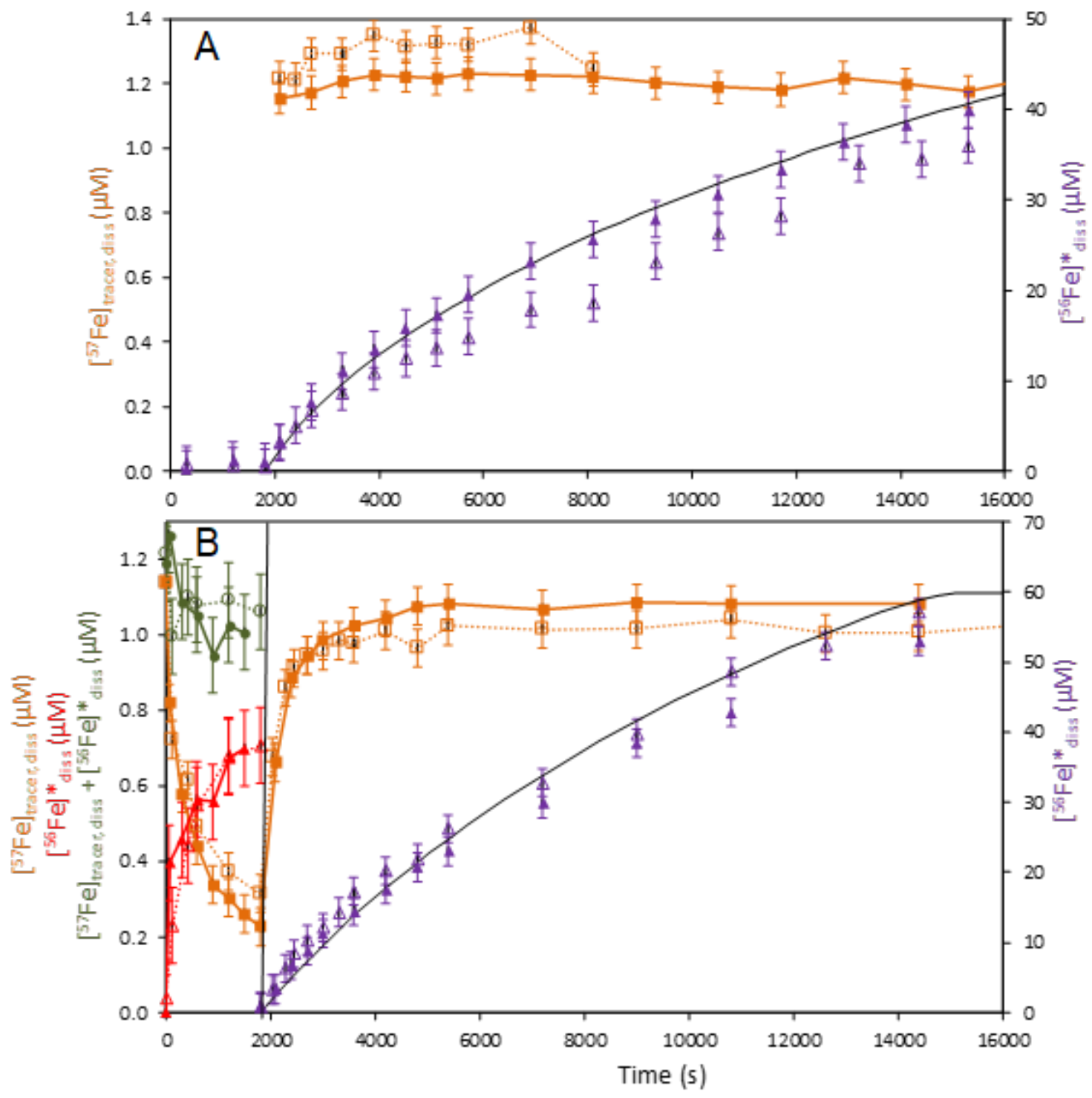

Figure 5. Dissolution of (1125 $\mu \mathrm{M}) \mathrm{Lp}$ at pH 6.0 under anoxic conditions catalyzed by addition of $1.2 \mu \mathrm{M} \mathrm{Fe}(\mathrm{II})$ as ${ }^{57} \mathrm{Fe}$ (II) either (a) $1800 \mathrm{~s}$ after the addition of $50 \mu \mathrm{M}$ EDTA or (b) before EDTA addition. Adsorption and isotopic exchange of added ${ }^{57} \mathrm{Fe}(\mathrm{II})$ were observed when (b) $60 \mu \mathrm{M}$ EDTA was added 1800 s after Fe(II). Symbols: (purple triangles, right axis) concentration of Fe released into solution by Lp dissolution (reported values of $\left[{ }^{56} \mathrm{Fe}\right]{ }^{*}$ diss correspond to the sum of all Fe-isotopes from Lp as described in Materials and Methods); (orange squares, left axis) concentration of the ${ }^{57} \mathrm{Fe}$ tracer remaining in or released back into solution where $\left[{ }^{57} \mathrm{Fe}\right]_{\text {tracer,diss }}$ was corrected for ${ }^{57} \mathrm{Fe}$ released from Lp; (red triangles, left axis) concentration of ${ }^{56} \mathrm{Fe}$ in solution resulting from isotopic exchange of added ${ }^{57} \mathrm{Fe}$ with ${ }^{56} \mathrm{Fe}$ in Lp ( $<1800 \mathrm{~s}$ ); (green circles, left axis) sum of dissolved Fe measured as $\left[{ }^{57} \mathrm{Fe}\right]_{\text {tracer, diss }}$ and $\left.\left[{ }^{56} \mathrm{Fe}\right]\right]^{*}$ diss. Results of duplicate experiments are shown in open and closed symbols (note that results shown in Fig. 5b with filled symbols were scaled to compensate for the addition of a lower concentration $(1.0 \mu \mathrm{M})$ of ${ }^{57} \mathrm{Fe}$ (II) in this experiment). Error bars correspond to the standard deviations of ICP-MS measurements obtained from repeated calibrations. Solid black lines show kinetic model fits (Table 1). 